\title{
Primary Papillary Serous Carcinoma of the Peritoneum
}

\author{
Jayakumar NM, Sangam PS, Grampurohit VU, Myagery AF \\ Department of Pathology, SDM College of Medical Sciences and Hospital, Sattur, Dharwad.
}

\begin{abstract}
Primary papillary serous carcinoma of peritoneum (PPSCP) is a rare type of primary peritoneal adenocarcinoma and is clinico-histopathologically indistinguishable from primary ovarian papillary serous carcinoma. A 70 -year- female presented with pain abdomen of 4 months duration. On examination partially mobile vague mass was present in the suprapubic region. Exploratory laparotomy revealed normal right ovary and the left ovary showed simple cyst. Nodular, firm tumour was seen arising from omentum and measured 20x13x9.3 cm. Microscopically tumour was composed of large sheets of polygonal cells having large hyperchromatic and pleomorphic nuclei and moderate amount of eosinophilic cytoplasm forming cribriform pattern and papillae. It has similar prognosis as that of ovarian malignancy. This case of extraovarian papillary serous carcinoma of peritoneum (EPSCP) is presented here for its rarity.
\end{abstract}

Keywords: malignant mesothelioma, papillary serous, peritoneum.

\section{INTRODUCTION}

Primary papillary serous carcinoma of peritoneum (PPSCP) is a rare type of primary peritoneal adenocarcinoma. Itisclinicallyand histopathologically indistinguishable from primary ovarian papillary serous carcinoma. PPSCP has become an established entity through several clinicopathological studies. ${ }^{1}$ PPSCP has been reported under many different names, such as extra-ovarian peritoneal serous papillary carcinoma, papillary serous carcinoma of peritoneum, and peritoneal serous carcinoma. ${ }^{2-4}$ All of these terms have led to great confusion amongst clinicians and pathologists. The most common presenting feature in patients with these tumours is chronic pelvic or abdominal pain. Most of the times, this tumor is discovered incidentally at laparotomy performed for other conditions..$^{5}$ Although this is biologically and histologically similar to ovarian carcinoma, this is a distinct clinicopathologic entity and could occasionally be encountered by the

\section{CORRESPONDENCE}

Dr Nirmala Mysore Jayakumar SDM College of Medical Sciences and Hospital, Dharwad, Karnataka, India.

Email: drnirmalamj@yahoo.com

Phone: 091-9845443073 gynaecologists. Therefore though rare, this tumor is not uncommon and hence is presented here.

\section{CASE}

A postmenopausal multiparous female of 70 years presented with pain abdomen of four months duration. Per abdominal examination showed a partially mobile vague mass of 24 weeks size in the suprapubic region extending up to umbilicus. Pelvic examination revealed retroverted uterus with free fornices and uterine movements were not transmitted to the mass. Ultrasonography showed a large solid lobulated mass in the pelvis extending upto umbilical level measuring 200x130x93mm involving deep of parietal wall. The relation of the tumour mass to other organs could not be made out. Investigations revealed markedly raised CA125 (2,421 IU/ml) level. CT scan of abdomen and pelvis was also done and it showed neoplastic growth of right ovarian origin with both solid and necrotic areas, extending into lower abdominal quadrants.

The papers in this journal are published under the terms of the Creative Commons Attribution License. Users are allowed to read, download, copy, distribute, print, search, or link to the full texts of the articles in this journal without asking prior permission from the publisher or the author. 
Exploratory laparotomy revealed a lobulated mass approximately measuring $20 \times 14 \times 9 \mathrm{~cm}$ arising from omentum and adherent to the abdominal wall and colon. Mass was not related to the ovaries. Right ovary was normal, left ovary showed thin walled cyst. Uterus, colon, stomach and liver were normal. No palpable lymph nodes were present. A probable surgical diagnosis of metastatic malignant tumour arising from the peritoneum was made. However, the primary site could not be traced during operative procedure. After releasing adhesions of tumour from colon and abdominal wall, tumour with omentum and left ovary was removed. Uterus and right ovary was retained. Postopertive CT chest was within normal limits.

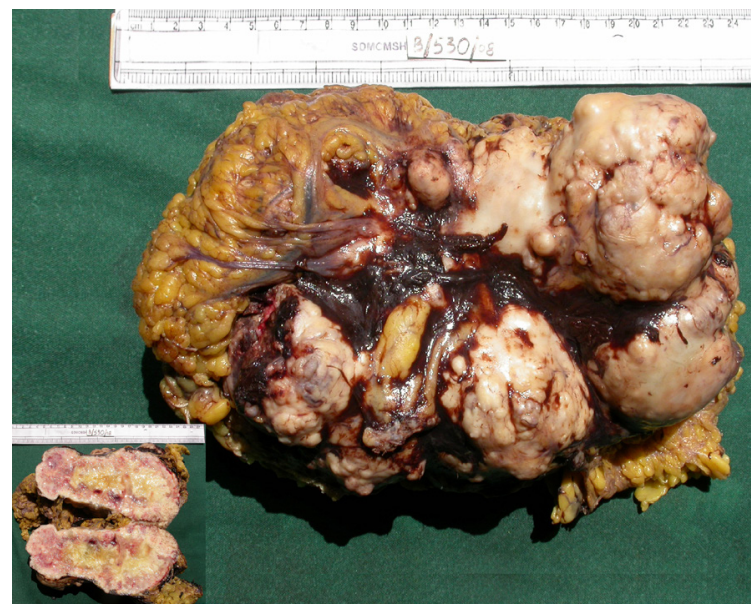

Figure 1. Well circumscribed multilobulated mass with surface covered by omentum. Inset shows cut section of tumour with central necrotic areas.

Macroscopically the tumour was nodular, firm and weighed $1395 \mathrm{gms}$ and measured $20 \times 13 \times 9.3 \mathrm{~cm}$ (Figure 1). Cut section was firm grey white with areas of necrosis (Figure 1 inset). Cut section of left ovary showed single cyst measuring $5.3 \times 4.5 \times 3$ $\mathrm{cms}$. Microscopically tumour was composed of large sheets of polygonal cells having large hyperchromatic pleomorphic nuclei and moderate amount of eosinophillic cytoplasm forming cribriform pattern and papillae with slender vascular core (Figure 2). Mitotic figures were abundant. Comedo type of necrosis was seen in the centre of the sheets. On immunohistochemistry tumour cells showed positivity for Epithelial Membrane Antigen (EMA) and S100 protein (Figure 3a, 3b). Left ovary showed simple cyst. With the above findings, diagnosis of high grade primary papillary serous carcinoma of the peritoneum (PPSCP) was suggested. Cisplatin-based combination chemotherapy was given, however patient succumbed to death after 7 months.

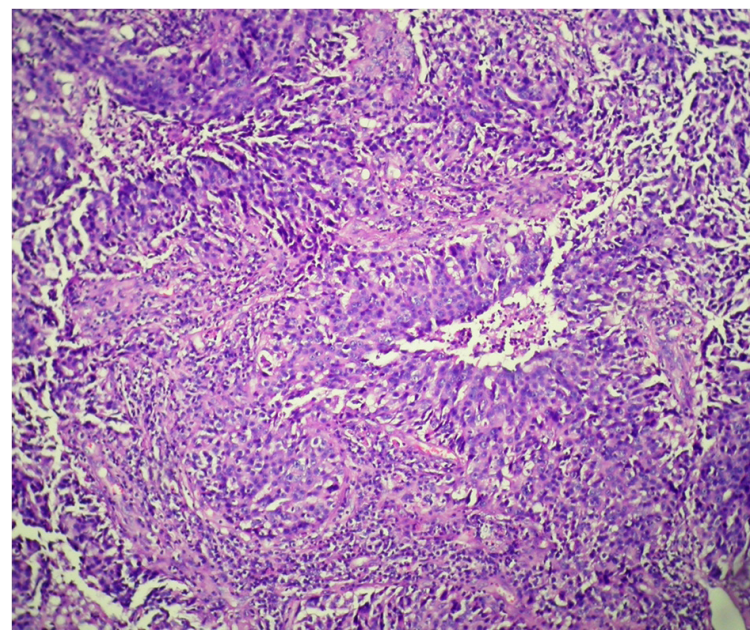

Figure 2. The tumour cells arranged in papillary pattern with high $\mathrm{N}$ : C ratio. [H\&E stain, 10X]

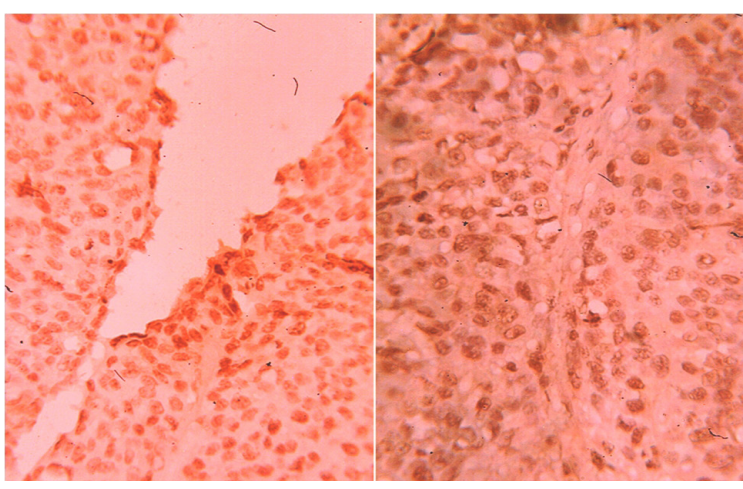

Figure 3. Immunohistochemical study of tumour cells showing EMA positivity (3a) \& S -100 positivity (3b).

\section{COMMENT}

Primary papillary serous carcinoma of the peritoneum (PPSCP) has been a recognized disease entity since it was first described by Swerdlow in 1959 as a case of Mesothelioma of the pelvic peritoneum resembling papillary cystadenocarcinoma of the ovary. ${ }^{6}$ However PPSCP is different from mesothelioma, which usually occurs in males older than 50 years of age with history of asbestos exposure and is rarely seen in women and children. ${ }^{7}$ PPSCP also differs from primary serous carcinoma of the ovary in that it may occur in women whose ovaries are normal or even previously excised.

Primary papillary serous carcinomas of peritoneum (PPSCP) resemble their ovarian counterparts on microscopic and immunohistochemical examination. Criteria for their separation from primary serous carcinoma of the ovary with peritoneal spread have been proposed by the Gynaecologic Oncology 
Group: (1) Both ovaries are either normal in size or enlarged by a benign process; (2) In the judgement of the surgeon and the pathologist, the bulk of the tumour is in the peritoneum and the extent of the tumour involvement at one or more extraovarian sites is greater than on the surface of the ovary; (3) Microscopic examination of the ovaries reveals no tumour, tumour confined to the surface epithelium with no evidence of cortical invasion; (4) The histologic and cytologic characteristics of the tumour are predominantly serous and similar or identical to those of ovarian serous papillary adenocarcinomas of any grade. ${ }^{6}$ All these criteria are well met in the histopathology of our patient and hence this diagnosis is suggested. It is now considered as an independent clinicopathologic entity and better understood as a neoplasm that arises from mesothelial cells under mullerian influence. ${ }^{8}$

PPSCP is grouped under the lesions of secondary mullerian system. Secondary mullerian system has been applied to pelvic and the lower abdominal mesothelium and the subjacent mesenchyme of females, on the basis of its close embryologic relationship with the primary mullerian system (mullerian ducts). ${ }^{19}$ The potentiality of this tissue is manifested by the existence in the peritoneal cavity of a large variety of metaplastic and neoplastic lesions that are analogues in all regards to those more commonly found in ovary, uterus or other organs in female genital tract. These lesions sometimes occur in association, not surprising in view of their related histogenesis and pathogenesis. ${ }^{10}$

To separate primary papillary serous carcinoma of the peritoneum (PPSCP) from papillary serous carcinoma of the ovary (PSCO), good immunohistochemical markers have not been identified so far. Immunohistochemistry (IHC) results showed that the response of PPSCP to some determinants is similar to that of PSCO, whereas in its response to other determinants it is similar to malignant mesothelioma. ${ }^{1}$ The IHC overlap among these three tumours may be explained by the notion that they have a common origin in the mesothelium, whereas differences may be related to the presence or absence of mullerian influence on the original mesothelium. Prognosis of PPSCP is similar to or worse than that of stage III ovarian serous carcinoma. ${ }^{5}$

\section{CONCLUSIONS}

Primary papillary serous carcinoma of the peritoneum though biologically and histologically is similar to ovarian carcinoma is a distinct clinicopathologic entity not uncommonly encountered by the gynaecologist. Hence, the diagnosis of PPSCP should be kept in mind whenever a patient presents as advanced ovarian tumor.

\section{REFERENCES}

1. Zhou J, Iwasa Y, Konishi I, Kan N, Kannagi R, Kobashi Y, et al. Papillary serous carcinoma of the peritoneum in women. A clinicopathologic and immunohistochemical study. Cancer. 1995;76:429-36.

2. Dalrymple J C, Bannatyne P, Russell P,Solomon H J, Tattersall MHN, Atkinson K, et al. Extraovarian peritoneal serous papillary carcinoma. A clinicopathologic study of 31 cases. Cancer. 1989;64:110-15.

3. Koutselini HA, Lazaris AC, Thomopoulou G, Papayannopoulou A, Kairi Vasilatou E. Papillary serous carcinoma of peritoneum: case study and review of the literature on the differential diagnosis of malignant peritoneal tumors. Adv clin Path. 2001;5(30):99-104.

4. Weir MM, Bell DA, Young RH. Grade 1 peritoneal serous carcinomas; a report of 14 cases and comparison with 7 peritoneal serous psammocarcinomas and 19 peritoneal serous borderline tumors. Am J Surg Pathol. 1998; 22(7):849-62.

5. Philip B, Clement. Diseases of the peritoneum. In: Kurman RJ, eds. Blaustein's Pathology of the Female genital Tract. $5^{\text {th }}$ ed. New Delhi: Springer-verlag;2004. p. 771-3.

6. Swerdlow M. Mesothelioma of the pelvic peritoneum resembling papillary cystadenocarcinoma of the ovary. Am J Obstet Gynecol. 1959;77:197-200.

7. Kannerstein M, Churg J, Mc Caughey WTE, Hill DP. Papillary tumors of the peritoneum in women: mesothelioma or papillary carcinoma. Am J Obstet Gynecol. 1977;127: 306-14.

8. August CZ, Murad T M, Newton M. Multiple focal extraovarian serous carcinoma. Int J Gynecol Pathol. 1985; 4:11-23.

9. Lauchlan SC. The secondary mullerian system revisited. Int J Gynecol Pathol. 1994;13:73-9.

10. Rosai J, eds. Rosai and Ackerman's Surgical Pathology. $9^{\text {th }}$ ed. Missouri: Elsevier;2004. p. 2386-8. 